\title{
Effects of Short-Term Clinical Art Therapy in Firefighters with Post-Traumatic Stress Risk
}

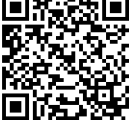

\author{
Soo-Ji Kang1, Sun-Hyun Kim*2 and Kwang-Hyun Baek*1,3 \\ ${ }^{1}$ Department of Medicine in General Graduate School, CHA University, Republic of Korea \\ ${ }^{2}$ Department of Clinical Art Therapy, CHA University, Republic of Korea \\ ${ }^{3}$ Department of Biomedical Science, CHA University, Republic of Korea
}

Submission: October 13, 2018; Published: November 21, 2018

*Corresponding author: Kwang-Hyun Baek and Sun-Hyun Kim, 335 Pangyo-Ro, Bundang-Gu, Seongnam-Si, Gyeonggi-Do 13488, Republic of Korea

Abstract

The purpose of this study is to identify event shock, anxiety, occupational and social functioning, and electroencephalogram (EEG) changes by conducting clinical art therapy (CAT) immediately after participants experience traumatic events. This study involved 100 firefighters from Seoul Metropolitan Fire and Disaster Headquarters in South Korea. During field activities, firefighters who experienced or witnessed two or more deaths, child death, the death of fellow firefighters, life-threatening accidents, suicide incidents, or assault were targeted.

From June 1 to December 31, 2015, researchers visited the fire stations to conduct a group survey and CAT sessions. Each CAT session lasted 60 minutes, and two sessions were provided. As for the test tools, a questionnaire regarding the traumatic event, along with EEG, impact of event scale-revised (IES-R), Beck Anxiety Inventory (BAI), social and occupational functioning assessment scale (SOFAS) were used. Before/after tests were conducted before the beginning of the first session and after the end of the second session.

After the firefighters engaged in CAT sessions, the level of IES-R ( $t=3.006, p=.003)$ and BAI $(t=3.030, p=.003)$ decreased while SOFAS ( $t=-$ $2.665, \mathrm{p}=.009$ ) increased. In addition, there was a positive change in the brain function index, showing a statistically significant change in six items.

This study shows that CAT can help reduce the impact of traumatic events. We hope that the findings and suggestions contained in this paper can contribute to reducing the psychological and psychological trauma of firefighters.

Keywords: PTSD; IES-R; Anxiety; Complementary and integrative medicine; EEG

Abbreviations: EEG: Electroencephalogram; CAT: Clinical Art Therapy; IES-R: Impact of Event Scale-Revised; BAI: Beck Anxiety Inventory; SOFAS: Social and Occupational Functioning Assessment Scale; BRQ: Basic rhythm quotient; SRQ: Self-regulation quotient; ATQ: Attention quotient; ACQ: Activity quotient; EQ: Emotion quotient; ASQ: Anti-stress quotient; CQ: Correlation quotient; BQ: Brain quotient

\section{Introduction}

Trauma first refers to a physical injury or shock caused by violence or aggressive behavior, and second; to an experience that causes psychological damage or pain [1]. Professional rescue workers (e.g., police and firefighters) commonly serve as responders to disasters or emergencies, and they are routinely exposed to traumatic events during the course of their duties [2]. Firefighters are not only responsible for preventing and fighting fires but are also charged with various other important tasks, such as rescuing victims and providing emergency medical aid. Often, firefighters are the first to arrive at the scene of violent or tragic events; therefore, they frequently have to handle victims' gruesome injuries or witness victims' death or even the deaths of their colleagues. For this reason, firefighters suffer from injuries or threats, and experience trauma either directly or indirectly $[3,4]$.

The prevalence rates of PTSD symptoms for US and Canadian city firefighters measured using IES were $22.2 \%$ and $17.3 \%$, respectively [5]. The rate of high-risk PTSD was $17.7 \%$ for firefighters working in the fire department of a Japanese city and was estimated using IES-R [6].

Firefighters have higher levels of anxiety and depression compared to other groups and are exposed to various mental illnesses [7]. The more traumatic events one experiences, the more likely they are to experience severe symptoms of posttraumatic stress (PTS) [8]. Firefighters require counseling and treatment programs because they are classified as a high-risk group in regard to PTS accompanied by fear, helplessness, and suffering caused by repeated exposure to trauma [9].

Since the issues of disaster, stress, and PTS are drawing more attention from the public, various prevention and treatment techniques have been suggested. Among the approximately 200 complementary therapies that currently exist, clinical art therapy (CAT) is an effective therapy for comprehensively assessing and 
improving physical, mental, psychological, social, and spiritual health. CAT is studied in the field of complementary and alternative medicine (CAM) and has already been applied in clinical practice as part of orthodox medicine [10].

CAT is a form of therapy that combines with art and medicine, evaluating (diagnosing) a patient's physical and mental condition through art activities; and improving treatment and mitigating symptoms of a disease [11]. CAT allows nonverbal communication in the treatment and mitigation of symptoms, thus aiding in mental outbursts that cannot be expressed in words. It facilitates the safe release of anxiety and other issues [12]. In many cases, psychological trauma is accompanied by clear traumatic images which remain edged in the memory for an extended time. Due to the trauma or mental shock experienced during an accident, patients become anxious when they face similar situations. Psychological trauma sometimes shuts down language processing, and the event is remembered as a nonverbal image and is reproduced visually [13].

CAT provides patients experiencing trauma with an opportunity to express their natural human desires, such as crisis, sorrow, and despair; and offers psychological support for patients to explore and overcome their trauma. It also attempts to help patients meaningfully explore the emotions and ideas related to acute or chronic trauma in order to facilitate their mental, emotional, and physical management [14]. As a result of these therapeutic effects, CAT, as a field of CAM, is effective for psychotherapy.

The final goal of therapeutic work in PTS is for patients to regain their level of functioning before the trauma occurred $[15,16]$. However, this does not mean that the patient returns to his/her previous state of trauma; but rather, that the patient is

Table 1: Program time, Art materials and CAT programs. able to accept the traumatic event and adapt to his/her daily life by integrating their experience into it [17].

Therefore, it is necessary to introduce immediate therapeutic interventions after exposure to trauma, as well as interventions for the management of stress after a crisis event. It is necessary to develop a prevention and treatment program that is capable of achieving psychological stability among firefighters, reducing the level of event shock, and positively affecting their physical health and social relationships. Further, there should be an opportunity to apply such programs in a systematic manner.

The purpose of this study is to identify event shock, anxiety, occupational and social functioning, and electroencephalogram (EEG) changes by conducting CAT immediately after patients experience traumatic events. In addition, we attempted to break out of the method limited to the conventional questionnaire and presented the results of EEG changes to verify the effectiveness of CAM.

\section{Materials and Methods}

\section{Participants and procedures}

The purpose of the program was to reduce the intensity of PTS that occurred during field activities, and to prevent mental problems. This study involved 100 firefighters from Seoul Metropolitan Fire and Disaster Headquarters in South Korea. Written informed consent was obtained from the participants before the study. The participants of the study were firefighters engaged in field activities. During field activities, firefighters who experienced two or more deaths, child deaths, deaths of fellow firefighters, life-threatening accidents, suicide incidents, or assault were targeted.

\begin{tabular}{|c|c|c|c|c|c|}
\hline Session & Program & Expectancy effect & & Program time & Art materials \\
\hline \multirow{4}{*}{1} & \multirow{4}{*}{$\begin{array}{l}\text { Recomposition of } \\
\text { masterpieces }\end{array}$} & Internal recognition & $10^{\prime}$ & Program introduction & Printed masterpieces \\
\hline & & Understanding of self-feelings & $10^{\prime}$ & Selection of paintings & $\begin{array}{l}\text { Oil pastel, pastel, watercolor, brush, } \\
\text { colored pencil, marker, pencil, eraser, } \\
\text { drawing paper }\end{array}$ \\
\hline & & & $25-30$ & $\begin{array}{c}\text { Reconstruct selected } \\
\text { paintings to create a picture }\end{array}$ & \\
\hline & & & $10-15^{\prime}$ & $\begin{array}{l}\text { Painting description and story } \\
\text { of group members }\end{array}$ & \\
\hline \multirow{3}{*}{2} & \multirow{3}{*}{ Free clay work } & $\begin{array}{l}\text { Feeling expression and self- } \\
\text { exploration }\end{array}$ & $10^{\prime}$ & program introduction & Clay, clay tools, water drawing paper \\
\hline & & Alleviation of negative stress & $30-40^{\prime}$ & Making Clay Works & \\
\hline & & Relaxation & $10-15^{\prime}$ & $\begin{array}{l}\text { Painting description and story } \\
\text { of group members }\end{array}$ & \\
\hline
\end{tabular}

Table Abbreviations: CAT: Clinical art therapy.

From June 1 to December 31,2015, researchers visited the fire stations to conduct a group survey and CAT sessions. The research was conducted at six fire stations and eight safety centers in Seoul. In this study, two clinical art therapy specialists, five clinical art therapists, and supervisors (professor of clinical art therapy/ professor of biomedical science) participated. One clinical art therapy specialist and two clinical art therapists visited each fire station. We conducted a pre- and post-test and the CAT, and two supervisors reviewed and advised on the pre- and post-test and program. 
Two CAT sessions, each lasting 60 minutes, were provided. Before/after tests were conducted before the beginning of the first session and after the end of the second session.

\section{Intervention}

Both the first session and the second session were conducted for 60 minutes except for the pre- and post-test. The program structure and materials are shown in Table 1. The presented materials were freely chosen and used.

The masterpieces presented 300 paintings by 30 artists from the 19th century to the present. In order to prevent the bias of the researchers in selecting the works of each artist, we used works that were officially published in the artists' work books. In addition, a description of each painter and a description of the work are also presented.

After presenting various masterpieces on the desk, one clinical art therapy specialist explained the program. 'These paintings are the works of painters, and they express their emotions. There may be a painter we know and some we do not know. Please select any two to three works from the various works. You can choose works that you empathize with or choose your favorite works. Then, reconstruct the selected works and freely express them on the drawing paper. In addition to the selected works, you may select other works. After completing the work, we will set a title for each picture, and take a moment to discuss the criterion used to select the painting and the work that each person expressed.'

Instructions for the program of the second session are as follows.

'Knead enough clay. When you have kneaded enough clay, express your feelings, thoughts, and experiences by touching the Table 2: The brain function quotient. clay freely. The work can be made in sculpture. Using water to knead the clay may feel different. '

Two clinical art therapists, acting as assistant therapists, explained to the subjects how to use the materials and helped the subjects who had difficulty expressing their works. Pre- and post-test results, the works' photographs, and consultations were recorded after the program was completed.

\section{Study tools}

Impact of event scale-revised: IES-R: The IES was developed by Horowitz for the purpose of studying the shock and adjustment process after a traumatic event, and it has been widely used in traumatic-experience studies [6]. In this study, the researchers employed a modified version of the IES-R scale, where Eun scaled down the original five-point scale [18]. The Korean version of the IES-R was standardized with good internal consistency $(\alpha=.93)$ [19].

Beck anxiety inventory: BAI: The BAI is a scale that was developed by Beck, Epstein, Brown and Steer [20]. This self-report test was designed to measure the level of anxiety among patient and non-patient groups, and it contains 21 questions. It evaluates mental and physical symptoms to identify the intensity of anxiety.

Social and occupational functioning assessment scale: SOFAS: The SOFAS was developed to measure social and job functioning [21]. The score is given in the minimum unit of ten points. Each step has been defined and its criterion has been described. This tool is focused only on functioning levels and does not include any measurement of symptoms. A higher score indicates high social functioning on the subject.

\begin{tabular}{|c|c|c|c|}
\hline Analyzing quotient & Hemisphere & Related frequency & Characteristics \\
\hline $\begin{array}{c}\text { Self-regulation quotient } \\
\text { (SRQ) }\end{array}$ & $\alpha$ wave, SMR, low $\beta$ wave & $\begin{array}{c}\text { Decision of brain autonomic nervous system controllability, rest, } \\
\text { attention, concentration decision }\end{array}$ \\
\hline $\begin{array}{c}\text { Basic rhythm quotient } \\
\text { (BRQ) }\end{array}$ & Left, right & eye closure state $\alpha$ wave, & $\begin{array}{c}\text { Decision of degree of brain development, stability and degree of } \\
\text { aging }\end{array}$ \\
\hline $\begin{array}{c}\text { Attention quotient } \\
\text { (ATQ) }\end{array}$ & Left, right & $\theta$ wave, SMR & $\begin{array}{c}\text { Decision of brain awakening degree, resistance to disease or } \\
\text { physical fatigue }\end{array}$ \\
\hline Activity quotient (ACQ) & Left, right & $\alpha$ wave, low $\beta$ wave & Decision of degree of brain activity \\
\hline Emotion quotient (EQ) & & Left $\alpha$ wave, right $\alpha$ wave & Decision of emotional average status \\
\hline $\begin{array}{c}\text { Anti-stress quotient } \\
\text { (ASQ) }\end{array}$ & Left, right & $\delta$ wave, high $\beta$ wave & Decision of balance degree of left or right brain \\
\hline $\begin{array}{c}\text { Correlation quotient } \\
\text { (CQ) }\end{array}$ & & $\begin{array}{c}\text { Correlation of left and right } \\
\text { brainwave }\end{array}$ & Total decision of brain function \\
\hline Brain quotient (BQ) & & All frequency & degree \\
\hline
\end{tabular}

Source: Korea Psychiatry Research Center

Electroencephalogram: EEG: EEG was measured using the Neurofeedback System (Braintech Corp, Korea) developed in the Korea Psychiatry Research Center. Neuro Harmony, a neurofeedback system, was implemented on the basis of twochannel brainwave measurements, which were performed in the frontal lobe using a bi-polar inductive method. This study measured and analyzed the change in brain waves from session 1 and session 2 pre- and post-CAT. The type and characteristics of the EEG are shown in Table 2.

The EEG in this study was performed on 14 firefighters who, at 25 points or more which is the cut-off point of the Korean version 
of the IES-R scale, were at risk of PTSD. PTSD diagnostic cut-off point was used in the reliability and validity study of the Korean version of the IES-R comparing the PTSD group and the normal group, with a sensitivity of 1.0 and the highest specificity score of 24/25 [18]. The classification of the PTSD risk group was based on the Korean version of the IES-R score of $24 / 25$ as the diagnostic cut point of PTSD.

\section{CAT program}

CAT was conducted in two programs.

The first program involves the reconstruction of masterpieces. As one of the various techniques of CAT, art therapy that uses masterpieces can lead to emotional relaxation and can reduce the burden of art activities. Through the appreciation of masterpieces, the participant may understand the psychological state and mental world of the piece's painter and simultaneously has an opportunity for self-reflection, thereby finding clues to healing. This technique allows anyone, not only trauma patients, to evaluate their current thinking and psychological state and experience healing [22]. CAT that uses masterpieces is performed in a way that imitates and transforms the masterpiece along with the appreciation of masterpieces. There is an aesthetic element that is experienced externally, but there is also an internal, logical, cognitive, and historical experience. Thus, the subject can understand their feelings and construct new meaning.
The second program involved free expression using clay work. Clay is one of the most familiar types of art media. Clay can be used for a variety of expressions and can allow one to creatively emanate their oppressed feelings. In this process, a psychological sense of liberation and satisfaction can be felt [21]. In addition, the soft touch of the clay can engender psychological relaxation [23]. The details of the program used in this study are shown in Table 1.

\section{Analysis}

To judge the effectiveness of CAT; IES-R, BAI, SOFAS, and EEG administered through pre- and post-tests were statistically analyzed using a paired t-test. We also analyzed correlation with BAI and SOFAS by the degree of IES-R. The data collected in this study were statistically analyzed using SPSS 20.0.

\section{Results}

\section{Participants}

The participant group $(\mathrm{N}=100)$ was composed of $88 \%$ males and $12 \%$ females whose ages ranged from 28 to 61 years (Table $3)$. In terms of age distribution, the largest age group was 3039 years, accounting for $53 \%$ of the participant group, followed by the $40-49$ years group accounting for $23 \%$ of the participant group. Therefore, $76 \%$ of the study participants were in their $30 \mathrm{~s}$ or $40 \mathrm{~s}$. They experienced an average of $4.76(\mathrm{SD}=3.13)$ traumatic events, which means, on average, that they experienced four to five traumatic events.

Table 3: Participants' characteristics and work.

\begin{tabular}{|c|c|c|c|}
\hline \multicolumn{2}{|r|}{ Classification } & Frequency (Subject Number) $(\mathrm{N}=100)$ & Percentage (\%) \\
\hline \multirow{2}{*}{ Gender } & Male & 88 & 88.0 \\
\hline & Female & 12 & 12.0 \\
\hline \multirow{4}{*}{ Age } & 20-29 years old & 15 & 15.0 \\
\hline & 30-39 years old & 53 & 53.0 \\
\hline & $40-49$ years old & 23 & 23.0 \\
\hline & Over 50 years old & 9 & 9.0 \\
\hline \multirow{10}{*}{ Work } & Fire spot and fire-cause investigation & 1 & 1.0 \\
\hline & Emergent relief & 58 & 58.0 \\
\hline & Ambulance driving & 15 & 15.0 \\
\hline & Rescue & 5 & 5.0 \\
\hline & Safety center & 2 & 2.0 \\
\hline & Prevention \& gas facility check & 1 & 1.0 \\
\hline & Disaster/catastrophe investigation & 2 & 2.0 \\
\hline & Response against accident spot & 2 & 2.0 \\
\hline & Command on accident spot & 1 & 1.0 \\
\hline & Firefighting & 13 & 13.0 \\
\hline \multicolumn{2}{|r|}{ Sum } & 100 & 100 \\
\hline
\end{tabular}

The largest sub-group was paramedics (58\%), who are frequently exposed to traumatic events due to the nature of their work. Particularly among paramedics, failing in CPR was recalled as a traumatic event, as they maintained a vivid memory of the event and experienced wild thoughts beyond their control. This indicates that paramedics experienced more traumatic events and showed more PTSD symptoms [24]. 


\section{Influence of CAT on IES-R, BAI, and SOFAS}

As shown in Table 4, after firefighters engaged in CAT, the level of IES-R ( $\mathrm{t}=3.006, \mathrm{p}=.003)$ and BAI $(\mathrm{t}=3.030, \mathrm{p}=.003)$ decreased and SOFAS ( $\mathrm{t}=-2.665, \mathrm{p}=.009)$ increased. Such a change is considered to be statistically significant. Therefore, it can be concluded that CAT positively contributed to lowering the IES-R and BAI, enhancing SOFAS among the firefighters.

Table 4: Changes in participants' IES-R, BAI, SOFAS level before and after CAT.

\begin{tabular}{|c|c|c|c|c|}
\hline \multirow{2}{*}{ Classification } & Before $(\mathbf{n = 1 0 0})$ & After $(\mathbf{n = 1 0 0})$ & \multirow{2}{*}{$\mathbf{t}$} & \multirow{2}{*}{$\mathbf{p}$} \\
\cline { 2 - 4 } & $\boldsymbol{M} \mathbf{S \boldsymbol { D }}$ & $\boldsymbol{M} \pm \boldsymbol{S D}$ & & \\
\hline IES-R & $8.51 \pm 9.66$ & $6.33 \pm 8.71$ & 3.006 & $.003^{*}$ \\
\hline BAI & $4.91 \pm 6.08$ & $3.78 \pm 5.42$ & 3.03 & $.003^{*}$ \\
\hline SOFAS & $84.17 \pm 9.78$ & $85.60 \pm 7.92$ & -2.665 & $.009^{*}$ \\
\hline
\end{tabular}

${ }^{*} \mathrm{p}<.05$.

Table Abbreviations: CAT: Clinical art therapy; IES-R: Impact of event scale-revised; BAI: Beck anxiety inventory; SOFAS: Social and occupational functioning assessment scale.

To examine the relationship between the intensity of the IES-R and the level of BAI and SOFAS, correlational analyses were conducted. The results showed that the intensity of the IES-R has a positive relationship with BAI ( $\mathrm{r}=.473, \mathrm{p}=.000)$, indicating that as the intensity of the IES-R increased, the level of BAI increased. However, SOFAS ( $\mathrm{r}=-.147, \mathrm{p}=.146)$ did not show a statistically significant correlation (Table 5). Firefighters expressed anxiety but scored highly on SOFAS. This suggests that they believe that the shock from the events that they chronically face does not affect their job functioning. As for the job itself, the study participants took pride in what they do and had a sense of responsibility. Therefore, they did not think that such experiences negatively affected their social and occupational functioning.

Table 5: Correlation between the IES-R and BAI, SOFAS $(\mathrm{N}=100)$.

\begin{tabular}{|c|c|c|c|}
\hline \multicolumn{2}{|c|}{ Classification } & BAI & SOFAS \\
\hline \multirow{2}{*}{ IES-R } & $\mathrm{r}$ & 0.473 & -0.147 \\
\cline { 2 - 4 } & $\mathrm{p}$ & $.000^{* *}$ & 0.146 \\
\hline
\end{tabular}

\section{${ }^{* *} \mathrm{p}<.001$}

Table Abbreviations: IES-R: Impact of event scale-revised; BAI: Beck anxiety inventory; SOFAS: Social and occupational functioning assessment scale.

\section{Influence of CAT on the change of EEG}

Fourteen firefighters with high IES-R scores were selected and EEG measurements were taken. Because this study was a single group study without a control group, EEG measurements were taken four times before and after the program. In the first session, all fourteen subjects completed the test. In the second session, eight subjects who did not complete the post-test were excluded and six subjects completed the test. According to the analysis of the change in EEG before and after sessions 1 and 2 of CAT, the score increased for most EEG indices (Table 6).

Table 6: Pre- and post-brain function change at session 1 and 2 of CAT program.

\begin{tabular}{|c|c|c|c|c|c|c|c|c|c|c|c|}
\hline \multirow{2}{*}{\multicolumn{2}{|c|}{$\begin{array}{c}\text { Session } 1 \\
\text { Classification }\end{array}$}} & Before $(n=14)$ & After $(n=14)$ & & \multirow{4}{*}{$\begin{array}{c}\mathbf{p} \\
0.151 \\
0.255\end{array}$} & \multirow{2}{*}{\multicolumn{2}{|c|}{$\begin{array}{c}\text { Session } 2 \\
\text { Classification }\end{array}$}} & \multirow{3}{*}{$\begin{array}{c}\text { Before }(n=6) \\
M \pm S D \\
76.50 \pm 8.61\end{array}$} & \multirow{3}{*}{$\begin{array}{c}\text { After }(n=6) \\
M \pm S D \\
81.50 \pm 4.08\end{array}$} & \multirow{3}{*}{$\frac{t}{-1.698}$} & \multirow{3}{*}{$\frac{\mathbf{p}}{0.15}$} \\
\hline & & $\mathrm{M} \pm \mathrm{SD}$ & $\mathrm{M} \pm \mathrm{SD}$ & \multirow{3}{*}{$\begin{array}{c}\mathbf{t} \\
-1.526 \\
-1.19\end{array}$} & & & & & & & \\
\hline \multirow{2}{*}{ BRQ } & Left, & $68.50 \pm 10.83$ & $73.71 \pm 12.00$ & & & \multirow{2}{*}{ BRQ } & Left & & & & \\
\hline & Right & $71.64 \pm 8.85$ & $74.28 \pm 10.61$ & & & & Right & $71.16 \pm 7.62$ & $82.33 \pm 7.62$ & -3.55 & $.016^{*}$ \\
\hline \multirow{3}{*}{ SRQ } & Relaxation & $25.85 \pm 7.33$ & $26.00 \pm 7.36$ & -0.111 & 0.913 & \multirow{3}{*}{ SRQ } & Relaxation & $27.16 \pm 6.46$ & $27.50 \pm 4.76$ & -0.126 & 0.904 \\
\hline & Attention & $19.71 \pm 5.38$ & $22.50 \pm 5.74$ & -1.67 & 0.119 & & Attention & $19.83 \pm 6.01$ & $23.66 \pm 2.65$ & -1.257 & 0.264 \\
\hline & Concentration & $24.50 \pm 5.89$ & $19.57 \pm 5.27$ & 2.417 & 0.031 & & Concentration & $20.83 \pm 7.57$ & $19.83 \pm 5.91$ & 0.393 & 0.71 \\
\hline \multirow{2}{*}{ ATQ } & Left, & $45.57 \pm 23.70$ & $57.21 \pm 23.96$ & -2.436 & $.030^{*}$ & \multirow{2}{*}{ ATQ } & Left & $44.50 \pm 23.21$ & $67.50 \pm 23.97$ & -2.46 & 0.057 \\
\hline & Right & $48.64 \pm 23.65$ & $56.21 \pm 23.21$ & -1.276 & 0.224 & & Right & $40.50 \pm 26.47$ & $68.50 \pm 22.11$ & -2.679 & $.044^{*}$ \\
\hline \multirow{2}{*}{ ACQ } & Left, & $53.85 \pm 11.56$ & $61.50 \pm 11.31$ & -3.177 & $.007^{*}$ & \multirow{2}{*}{ ACQ } & Left & $48.66 \pm 16.36$ & $57.00 \pm 17.23$ & -1.716 & 0.147 \\
\hline & Right & $52.64 \pm 11.63$ & $61.78 \pm 13.70$ & -3.561 & $.003^{*}$ & & Right & $44.83 \pm 17.90$ & $58.16 \pm 15.94$ & -2.633 & $.046^{*}$ \\
\hline EQ & & $79.14 \pm 7.70$ & $80.42 \pm 8.06$ & -0.759 & 0.462 & EQ & & $77.33 \pm 7.14$ & $86.33 \pm 6.97$ & -3.279 & $.022^{*}$ \\
\hline \multirow{2}{*}{ ASQ } & Left, & $68.50 \pm 17.76$ & $76.50 \pm 21.61$ & -1.828 & 0.091 & \multirow{2}{*}{ ASQ } & Left & $72.16 \pm 16.36$ & $87.50 \pm 19.39$ & -1.826 & 0.127 \\
\hline & Right & $68.28 \pm 20.11$ & $77.92 \pm 17.70$ & -2.241 & $.043^{*}$ & & Right & $69.16 \pm 16.29$ & $89.66 \pm 14.63$ & -2.713 & $.042^{*}$ \\
\hline CQ & & $80.92 \pm 8.25$ & $80.00 \pm 7.93$ & 0.654 & 0.525 & CQ & & $71.66 \pm 18.14$ & $78.33 \pm 8.59$ & -0.859 & 0.429 \\
\hline BQ & & $63.85 \pm 8.37$ & $65.78 \pm 8.88$ & -1.296 & 0.217 & BQ & & $59.66 \pm 10.98$ & $69.83 \pm 8.51$ & -4.164 & $.009 *$ \\
\hline
\end{tabular}

* p <.05

Table Abbreviations: CAT: Clinical art therapy; BRQ: Basic rhythm quotient; SRQ: Self-regulation quotient; ATQ: Attention quotient; ACQ: Activity quotient; EQ: Emotion quotient; ASQ: Anti-stress quotient; CQ: Correlation quotient; BQ: Brain quotient

After the session, there was a statistically significant change in the left brain ( $\mathrm{t}=-2.436, \mathrm{p}=.030)$ for the attention quotient (ATQ), the left $(\mathrm{t}=-3.177, \mathrm{p}=.007)$ and right $(\mathrm{t}=-3.561, \mathrm{p}=.003)$ brain for the activity quotient (ACQ), and the right brain ( $\mathrm{t}=-2.241, \mathrm{p}=.043$ ) for the anti-stress quotient (ASQ). additionally, after the second CAT session, there was a statistically significant change in the right brain ( $\mathrm{t}=-3.550, \mathrm{p}=.016)$ for the basic rhythm quotient (BRQ), the right brain ( $\mathrm{t}=-2.679, \mathrm{p}=.044$ ) for the attention quotient (ATQ) and the emotion quotient (EQ) ( $\mathrm{t}=-3.279, \mathrm{p}=.022)$, and the right brain $(\mathrm{t}=-2.713, \mathrm{p}=.042)$ for the ASQ and the brain quotient (BQ) ( $\mathrm{t}=-$ $4.164, \mathrm{p}=.009)$. 


\section{Discussion}

This study aimed to identify IES-R, BAI, and SOFAS and EEG changes by conducting CAT after participants experienced traumatic events.

CAT caused a positive change in emotional behavior. Scores on the IES-R showed a statistically significant decrease after CAT. In addition, statistically significant changes were found for the BAI and SOFAS. This means that secondary issues that may arise from the impact of a traumatic event can be prevented through CAT.

The degree of IES-R negatively affected BAI. This means that anxiety increases with increase in traumatic incidents. However, there was no significant correlation between the IES-R and SOFAS. This is because most study participants experienced continuous trauma that often became chronic, and they did not think that they would leave their job because of their symptoms. Most of the participants reported seemingly better conditions than the reality.

Analysis of the EEG showed statistically significant changes in the left and right brain for the ATQ the left and right brain for the ACQ the right brain for the ASQ, and the right brain for the BRQ, $\mathrm{EQ}$, and BQ. Most of the items in the eight EEG indices showed a positive change after CAT, with a statistically significant change for six items.

After the first and second CAT sessions, a positive change in the left and right brain for the ATQ was found. A high ATQ indicates that the brain is in a clearly awakened state and that immune functioning is high. If either part of the ACQ is too high or too low, an imbalance of EEG, such as emotional instability, anxiety, language impairment, or memory loss, may arise, which could develop into a disease [25]. However, the mean score was elevated evenly in the left and right brain after the therapy. For the ASQ mean scores showed positive changes in the left and right hemispheres, but the results were statistically significant only in the right hemisphere. Additionally, the ASQ can be calculated by the mutual association of the delta $(\delta)$ wave and high beta $(\beta)$ wave, indicating resistance to physical and mental stress due to environmental factors. There was a significant change in the ASQ and $\mathrm{BQ}$ after both sessions of CAT. These results indicate that CAT increases the ability to resist stress. A higher score indicates lower resistance to disease due to greater fatigue, while a higher antistress index indicates higher resistance to disease [26,27]. This means that CAT can increase resilience to stress. Changes in the EQ and BQ were observed after the second session of art therapy. The average score of the EQ rose from active (77.33) to the highest level (86.33), and the BQ increased from the mid-low level (59.66) to the middle level (69.83). The subjects were thus emotionally stabilized and showed a positive change in the BQ after therapy. Positive changes in brain waves were observed in this study despite the short-term period of the therapy; thus, more positive changes may be observed if the treatment is continued for a longer period.

Firefighters who experience traumatic events belong to a high PTS-risk group. Secondary trauma is related to the development of PTSD [28], and it has been reported that if one is exposed to secondary trauma while already suffering trauma or helping others who have experienced trauma, a stress response can be triggered. Secondary traumatic stress can weaken physical and mental functions [29]. As firefighters are constantly exposed to traumatic events, it is necessary to institute a system that starts with PTS prevention and subsequently manages it. There are hardly any studies showing that indirect exposure to death in a single disaster may increase the risk of PTSD. Therefore, it is necessary to conduct additional studies that investigate repeated exposure to trauma in high-risk occupations [30,31].

In order to minimize the effects of personal experience with art, researchers selected media that would have psychological effects without imposing a burden on those who were new to art. Firefighters wanted to be involved in a way that did not hinder their work. In CAT, a process of pouring out one's emotions and exploring one's inner self took place. Firefighters had no way to express their problems or difficulties, and they had to endure long hours of work, low rewards, and tension. They were also worried about the disadvantages they might face for receiving psychological treatment at work. These factors make it difficult to provide proper prevention and treatment.

This program should be further investigated with a longterm plan for the continuing decline in post-traumatic stress due to short-term psychological intervention. In addition, research should be preceded by a psychological intervention for prevention before traumatic events occur. It is also important to recognize that firefighters are aware of the problem and can ask for help.

Although it may be difficult to judge the reliability of CAT in a single PTS risk group, emotionally and physically positive changes occurred after short-term treatment in this study. This suggests that long-term intervention may have a greater positive effect. This study also suggested that CAT can be performed shortly after experiencing traumatic events, thereby lowering the trauma shock and positively affecting anxiety and job function, which is necessary for psychological support.

\section{Conclusion}

This study shows that CAT can help reduce the impact of traumatic events. Many studies on the PTS of firefighters refer to the need for psychological trauma treatment, and state that offering psychological intervention immediately after the experience of a traumatic event would be meaningful. Most papers on the psychotherapy of firefighters exposed to trauma were based on self-administered questionnaires. In general, the interest in CAM among health professionals is not encouraging. In this study, we have attempted to present the scientific basis for the efficacy of CAT, which is a CAM, by showing the EEG changes of firefighters with a high score on the IES-R.

We hope that the findings and suggestions contained here can contribute to reducing the psychological and physiological trauma of firefighters. 


\section{Acknowledgment}

We would like to thank the clinical art therapists who helped us with this study: Ms. Yu-Rim Kang, Ms. Yeong-Gi Jang, Ms. ChangBae Son, Ms. Byeong-Jun Jeon, and Ms. Hye-Young Lee. This study was supported by the Ministry of the Interior and Safety, Republic of Korea [2014-0068].

\section{References}

1. Dictionary (1995) Random House. New York, USA.

2. Beaton RD, Murphy SA (1995) Working with people in crisis: Research implications. In: Figley CR, ed. Compassion fatigue: Coping with secondary traumatic stress disorder in those who treat the traumatized. New York, NY: Routledge, USA, pp. 51-81.

3. Baik JH, Jung YE, Chae JM, Myong, JP, Yim HW, et al. (2010) Effects of vicarious trauma on mental health in firefighters. Anxiety Mood 6: 6570 .

4. Lee SH, Kim SJ, Sim M, Yoo SY, Won SD, et al. (2015) Mental health of disaster workers. Psychiatry Investig 54(2): 135-141.

5. Horowitz M, Winer N, Alvarez W (1979) Impact of event scale: a measure of subject stress. Psychosom Mes 41(3): 209-18.

6. Weiss DS, Marmar CR (1997) The Impact of Event Scale-Revised. In: Wilson JP, Keane TM, (Eds), Assessing psychological trauma and PTSD. Guilford Press, New York, USA, pp. 399-411.

7. Guidotti TL (1992) Human factors in firefighting: ergonomic-, cardiopulmonary-, and psychogenic stress-related issues. Int Arch Occup Environ Health 64(1): 1-12.

8. Choi HK (2010) Effects of traumatic events on posttraumatic stress disorder, burnout, physical symptoms, and social and occupational functions in Korean firefighters. Unpublished doctoral dissertation, Ajou University.

9. Im HH (2011) Post-traumatic stress and related factors in firefighters, Unpublished Master's Thesis, Science Graduate School InJe University.

10. Chun SI (2006) The role of art therapy in integrated medicine. Journal of the Korean Academy of Clinical Art Therapy 1(1): 40-49.

11. Kim SH (2006) Understanding of clinical art therapy. Hakjisa, Seoul, Republic of Korea, pp. 420.

12. Kim SH, Chang YY, Kim BN, Kwon BJ, Jang EH (2009) A Clinical Study of Art Therapy for Children Who Witnessed a Tragic Accident J of Korean Soc of School Health 23(2): 143-150.

13. Gilroy A (2006) Art therapy, research, and evidence-based practice. Sage, London, England, pp.176.

14. Kim SH (2012) Post-traumatic stress disorder and clinical art therapy. Idam Book, Seoul, Republic of Korea, pp.209.

15. Horowitz MJ (1986) Stress-response syndromes: A review of posttraumatic and adjustment disorders. Psychiatric Services 37(3): 241-249.
16. Figley CR (1988) Post-traumatic family therapy. Post-traumatic therapy and victims of violence. Brunner/Mazel, New York, USA, p. 373.

17. Kim SJ, Kim H (2000) Posttraumatic stress disorder. Hakjisa, Seoul, Republic of Korea, pp.172.

18. Eun HJ, Kwon TW, Lee SM, Kim TH, Choi MR, et al. (2005) A study on reliability and validity of the Korean version of impact of event scalerevised. Psychiatry Investig 44(3): 303-310.

19. Lim HK, Woo JM, Kim TS, Kim TH, Choi KS, et al. (2009) Reliability and validity of the Korean version of the Impact of Event Scale-Revised. Compr Psychiatry 50(4): 385-390.

20. Beck AT, Epstein N, Brown G, Steer RA (1988) An inventory for measuring clinical anxiety: Psychological properties. J Consult Clin Psychol 56(6): 893-897.

21. Morosini P, Magliano L, Brambilla L, Ugolini S, Pioli R (2000) Development, reliability, and acceptability of a new version of the DSM IV Social and Occupational Functioning Assessment Scale (SOFAS) to assess routine social functioning. Acta Psychiatra Scand 101(4): 323329.

22. Baik JY (2016) A study to activate pottery psychotherapy to prevent stress. KSCA 13(3): 83-97.

23. Choi YS (2016) The effects of clay therapy program using ceramic works on psychological transformation of middle-aged women. Doctoral thesis, Myongji University.

24. Marmar CR, Weiss DS, Metzler TJ, Delucchi KL, Best SR, et al. (1999) Longitudinal course and predictors of continuing distress following critical incident exposure in emergency services personnel. J Nerv Ment Dis 187(1): 15-22.

25. Gotlib IH (1998) EEG alpha asymmetry, depression, and cognitive functioning. Cogn Emot 12(3): 449-478.

26. Peniston EG, Kulkosky PJ (1989) Alpha-theta Brainwave training and $\beta$-endorphin levels in alcoholics. Alcohol Clin Exp Res 13(2): 271-279.

27. Peniston EG, Marrinan DA, Deming WA, Kulkosky PJ (1993) EEG alphatheta brainwave synchronization in Vietnam theater veterans with combat-related post-traumatic stress disorder and alcohol abuse. Advances in Medical Psychotherapy 6(7): 37-50.

28. Friedman MJ, Resick PA, Bryant RA, Brewin CR (2011) Considering PTSD for DSM 5. Depress Anxiety 28(9): 750-769.

29. Cieslak R, Shoji K, Douglas A, Melville E, Luszczynska A, et al. (2014) A meta-analysis of the relationship between job burnout and secondary traumatic stress among workers with indirect exposure to trauma. Psychol Serv 11(1): 75-86.

30. Berninger A, Webber MP, Cohen HW, Gustave J, Lee R, et al. (2010) Trends of elevated PTSD risk in firefighters exposed to the World Trade Center disaster: 2001-2005. Public Health Rep 125(4): 556-566.

31. Zimering R, Gulliver SB, Knight J, Munroe J, Keane TM (2006) Posttraumatic stress disorder in disaster relief workers following direct and indirect trauma exposure to Ground Zero. J Trauma Stress 19(4): 553-557. 
